\title{
Reflexões contemporâneas do campo científico do Serviço Social sobre a formação
}

\author{
Ana Lúcia Suárez Maciel \\ Pontifícia Universidade Católica do Rio Grande do Sul (PUCRS)
}

Reflexões contemporâneas do campo científico do Serviço Social sobre a formação

Resumo: O artigo tematiza a formação em Serviço Social problematizando sua relação com a política de educação superior vigente, com a produção de conhecimento e com o pensamento dos pesquisadores da área. É uma pesquisa qualitativa empreendida a partir de dados coletados em fontes documentais, bibliográficas e empíricas, sendo o seu tratamento feito à luz da análise de conteúdo. A primeira seção apresenta uma discussão acerca dos rebatimentos da política de educação superior na formação. Em seguida apresenta o estado da arte sobre a categoria central do artigo e conclui sistematizando as contribuições dos líderes dos grupos de pesquisa na área.

Palavras-chave: Formação. Serviço Social. Ensino superior. Política de educação superior. Campo científico.

\section{Contemporary Reflections from the Scientific Field of Social Work about Education}

Abstract: This article considers education in social work by problematizing its relationship with current higher education policies, with the production of knowledge and with the thinking of researchers in the field. It is a qualitative study based on data collected from documental, bibliographic and empiric sources, which are treated using content analysis. The first section presents a discussion about the influence of higher education policy on education. It then presents the latest thinking about the central focus of the article and concludes by systematizing the contributions of leaders of research groups in the field.

Keywords: Education. Social Work. Higher education. Higher education policy. Scientific field. 


\section{Introdução}

Em 2016 o Serviço Social estará completando oitenta anos no Brasil. Amadurece em uma conjuntura e realidade social que sofreram importantes alterações, desde o surgimento da profissão até a atualidade, requerendo dos seus profissionais e pesquisadores a apreensão das mesmas assim como a capacidade de prospectar o futuro profissional. Este artigo se propõe a compartilhar dados obtidos numa pesquisa que problematiza a formação em Serviço Social a partir da apreensão de suas tendências e desafios contemporâneos, e na sua interface com a política de educação superior. Adota dois movimentos metodológicos: o primeiro elegeu uma técnica de coleta empírica tendo como sujeitos os líderes dos grupos de pesquisa da área, para se posicionarem acerca da realidade presente e futura da formação em Serviço Social ${ }^{1}$. O segundo elegeu uma técnica documental voltada para o mapeamento, tratamento e análise de uma das fontes oriundas da produção de conhecimento da área (teses e dissertações elaboradas nos Programas de Pós-Graduação da área) através do Portal da Coordenação de Aperfeiçoamento de Pessoal de Nível Superior (CAPES), objetivando a elaboração do estado da arte sobre formação a partir da identificação dos trabalhos, dos temas mais incidentes e das suas contribuições. Posteriormente, os dados coletados foram analisados e tratados à luz da metodologia de análise de conteúdo proposta por Pagés et all. (1990).

\section{A conjuntura da política de educação superior e seus rebatimentos no Serviço Social no século 21}

A formação em Serviço Social no Brasil, em 2016, permanece sendo impactada e transformada por uma conjuntura marcada por dois fatores principais: 1) a política de educação superior vigente no país, que tem sua gênese na Lei de Diretrizes e Bases da Educação (LDB) de 1996 e nos movimentos posteriores do Estado na gestão dessa política, o que tem resultado num crescimento desmedido e, predominantemente, privado dos cursos na área e, consequentemente, na ampliação do contingente de profissionais; 2) o amadurecimento acadêmico e político da profissão que se expressa pela produção do conhecimento e pelos movimentos organizativos da categoria para garantir a direção social e o respectivo projeto de formação da profissão (ABEPSS, 1996).

No que se refere à política de educação superior vigente no país, destacamos as influências de um conjunto de documentos que foram produzidos por organizações internacionais (Banco Mundial, Organização Mundial do Comércio, Organização das Nações Unidas para a Educação, a Ciência e a Cultura e Organização para a Cooperação e Desenvolvimento Econômico) na década de 1990 e no início do século 21, cujo teor esteve centrado na realização de diagnósticos acerca do ensino superior e de uma série de recomendações aos países em desenvolvimento para melhorar o acesso da população a este nível de ensino. Em síntese, $\mathrm{o}$ que esses documentos apontavam e propunham pode ser compilado nos seguintes aspectos: fomento à diferenciação das instituições de ensino superior (universidades, centros universitários e faculdades, com escopos de atuação e funções bem definidas e diferenciadas), incentivo à diversificação das fontes de financiamento (públicas e privadas, nesta última, inclusive, com incentivo à parceria público-privada e aos incentivos fiscais), redefinição do papel do Estado no ensino superior (enfatizando o papel de regulador e avaliador em detrimento do de executor) e adoção de políticas voltadas para a qualidade e a equidade (visando ampliação do acesso da população a este nível de ensino) e, também, adotando modelos de gestão empresariais para "mensurar" a qualidade que, progressivamente, passa a ser compreendida como desempenho e produto final, em detrimento do processo, conteúdo e relevância desse ensino.

Essa política vem incidindo na formação em Serviço Social de inúmeras formas (MACIEL, 2006; LIMA, 2007; DAHMER, 2008) e, infelizmente, há um consenso na categoria de que as consequências da mesma vêm alterando a geografia da formação e colocando em risco a qualidade do seu projeto de formação, bem como as condições para o exercício profissional, em termos de operacionalização desse trabalho, remuneração e status profissional. Ao recorrermos aos dados quantitativos que indicam o número de cursos, de alunos, a modalidade do ensino e a natureza da instituição de ensino podemos confirmar essas análises.

Os dados do último Censo da Educação Superior (INEP, 2013) indicaram a existência de 376 cursos (304 em instituições privadas e 72 em instituições públicas) de Serviço Social no país, sendo que 18 deles ofertam o curso na modalidade à distância (17 em instituições privadas e um em instituição pública). Desta totalidade, 154 instituições (41\%) são universidades, 51 (13\%) são Centros Universitários, 170 (45\%) são faculdades e um $(0,2 \%)$ é Centro Federal de Educação Técnica. É importante destacar que a modalidade de ensino à distância teve seu início, na área, no ano de 2006 e, no ano de 2010, já contabilizava 65.913 alunos matriculados. Nesse mesmo ano (2010), segundo a mesma fonte (INEP), a totalidade dos cursos de Serviço Social era de 309 (269 privadas e 40 públicas). No ano de 2012, dado mais recente que podemos acessar 
através do referido censo, o número de oferta de vagas para o curso de Serviço Social foi de 120.789 (76.652 na modalidade à distância e 44.137 na modalidade presencial). Destaca-se que, no ano de 2008, essas instituições ofertaram quase 200 mil vagas para o curso, o que nos permite inferir que a modalidade à distância foi um atrativo significativo para o mercado privado e, portanto, o principal responsável pelo salto quantitativo dos indicadores referentes à formação na contemporaneidade.

Com base nesses dados, é possível afirmar que essa formação vem se expandido velozmente em instituições privadas (80\%), do tipo faculdade (45\%) e na modalidade à distância. Se, no ano de 2001, eram 101 cursos de Serviço Social, em uma década tivemos uma expansão de 265\%, com a totalização dos 376 cursos já referidos. Em decorrência da expansão rápida do ensino superior privado, particularmente protagonizada pela modalidade do ensino à distância na área, tem ocorrido um crescimento significativo no quadro de assistentes sociais nos últimos anos, bem como gerado implicações na qualidade acadêmica dessa formação. Essa massificação e o comprometimento da qualidade no processo formativo "facilitam a submissão dos profissionais às demandas e "normas do mercado', tendentes a um processo de politização à direita da categoria" (IAMAMOTO, 2014, p. 629). O avanço quantitativo de profissionais no mercado de trabalho está diretamente relacionado ao aumento de desemprego, pois dificilmente a sua oferta poderá acompanhar o contingente de profissionais "em uma conjuntura recessiva, pressionando o piso salarial e a precarização das condições de trabalho, aumentando a insegurança no emprego e a concorrência no mercado profissional de trabalho" (IAMAMOTO, 2014, p. 630). Segundo dados do conjunto CFESS (2016), o Brasil tem hoje aproximadamente 170.000 (cento e setenta mil) profissionais com registro e é o segundo país no mundo em quantitativo de assistentes sociais, ficando atrás somente dos Estados Unidos.

Quanto à agenda política da categoria profissional, destaca-se, no que diz respeito à formação em Serviço Social, um conjunto de iniciativas que expressam a busca pela garantia da qualidade e do projeto de formação vigente. Alia-se a esses indicadores, a preocupação da categoria profissional, representada pelas suas organizações profissionais (ABEPSS, CFESS, ENESSO) em garantir a qualidade da formação. Como evidências dessa preocupação se pode ilustrar, como exemplos: a aprovação da Política Nacional de Estágios; a Resolução sobre Supervisão Direta, os Planos de Lutas em defesa do trabalho e da formação e contra a precarização do ensino superior; as campanhas que sinalizaram a incompatibilidade da adoção da modalidade do ensino à distância na área, entre outras tantas iniciativas que colocam a formação numa das pautas principais da profissão no século 21 .

Uma das estratégias para apreender como a formação vem sendo problematizada, na área do Serviço Social, está no seu próprio campo científico. Bourdieu (1983) propõe a noção de campo, como categoria analítica, para enfatizar a existência de um espaço propriamente social, constitutivo da dinâmica da produção cultural em seus diversos âmbitos. Dedica especial atenção à produção científica, contrapondo a hipótese do campo a duas tradições antagônicas. De um lado, a ideia de uma ciência pura, engendrando-se a si mesma num processo de perpetuação, numa espécie de partenogênese, completamente independente do mundo social. De outro lado, a ideia de uma ciência escrava, caracterizada por sua subordinação ao contexto e sujeição a todas as demandas político-econômicas. O campo científico, de acordo com Bourdieu (1983, p. 20), é um universo intermediário entre os dois polos, lugar onde "estão inseridos os agentes e as instituições que produzem, reproduzem ou difundem [...] a ciência".

Assim, empreendemos um caminho metodológico que buscou estabelecer contato com o campo científico do Serviço Social, com vistas a indicar tendências e desafios para a formação na atualidade, em face da conjuntura da política de educação superior brasileira, bem como com o intuito de identificar a contribuição desse campo para a apreensão e debate sobre esse objeto de estudo.

\section{O estado da arte sobre formação no século 21}

A partir do diálogo com as análises de Kameyama (1998), Silva e Carvalho (2005), Almeida e Mendes (2014) e Maciel (2014; 2015), pretendemos evidenciar a configuração da produção de conhecimento sobre formação, nessa trajetória histórica, bem como as suas principais configurações e contribuições no século 21. Para tanto, recorremos às produções que antecedem este século/década, com vistas a recuperar a trajetória histórica dessa produção.

Kameyama (1998) realizou um balanço da produção de conhecimento em Serviço Social no período de 1975 a 1997, quando totalizou 1.028 trabalhos (teses e dissertações), produzidas em oito Programas de Pós-Graduação em Serviço Social, sendo 2 doutorados e 8 mestrados. Dentre as temáticas mais incidentes, destacaram-se: a prática profissional (15\%), a Política Social (12\%) e a Formação Profissional (11\%). Ocupando o terceiro lugar nas produções desse período, a Formação Profissional refletia, especialmente, os 
desafios postos pela implantação do currículo de 1982 em que, grande parte dos estudos, realizou um "resgate do debate vivenciado pelos docentes na elaboração do currículo mínimo nas suas unidades de ensino" (KAMEYAMA, 1998, p. 13). Nos anos finais de 1980, emergia "a preocupação com o ensino da disciplina 'métodos de intervenção' e 'pesquisa"” (KAMEYAMA, 1998, p. 13). No fím da década de 1990, houve uma ênfase no papel do Assistente Social em equipes multidisciplinares, a fim de constituir a especificidade profissional (KAMEYAMA, 1998).

Conforme dados da pesquisa de Silva e Carvalho (2005), no período de 1998 a 2002, houve uma expansão significativa do número de Programas de Pós-Graduação em Serviço Social, triplicando o número de mestrados que passaram de 8 a 24, assim como quadriplicaram o número de cursos de doutorado de 2 para 9 . Ao analisarem a produção de conhecimento em Serviço Social, a partir das teses e dissertações (dentre outras fontes bibliográficas), no referido período, as autoras constataram que dos 760 trabalhos produzidos nesse período, os que se referiram ao eixo da Formação Profissional representaram apenas 4,6\% do total, o que revela uma queda de quase $7 \%$ da produção no período anterior.

Igualmente se destaca os dados que as autoras obtiveram na pesquisa sobre os 30 anos da Revista Serviço Social e Sociedade (1979 a 2009), pois ao compararem a incidência das temáticas por décadas (19791989/1990-1999/2000-2009), evidenciaram que de 15 indicações, na primeira década, passaram a ser 12 indicações na segunda década, decaindo para apenas três indicações na última década (até 2009).

Com vistas a atualizar os dados sobre a produção de conhecimento acerca da formação em Serviço Social, apresentamos os dados obtidos na pesquisa que estamos desenvolvendo sobre o tema (Maciel, 2014; 2015). No que se refere ao crescimento da pós-graduação na área, permanece a tendência da sua ampliação no período atual, pois dados obtidos em 2015 (CAPES, 2015) indicaram a existência de 31 cursos de mestrado e 15 de doutorado. Isso revela que, em pouco mais de uma década, houve uma ampliação de $22 \%$ dos cursos de mestrado e $40 \%$ dos cursos de doutorado. Ao nos debruçarmos nos resumos das teses e dissertações do referido, utilizando as ferramentas de busca avançada do Banco de Teses da Capes na Área de conhecimento do Serviço Social foram encontradas 912 produções (já excluídas as 42 produções na área de Economia Doméstica), sendo 764 dissertações e 148 teses. Destas, 93 se vinculam a temática da Formação, sendo 20 teses $(22 \%)$ e 73 dissertações (78\%); $40 \%$ foram produzidas na primeira década do século 21 (até 2010) e 60\% nos dois anos subsequentes: $29 \%$ em 2011 e 31\% em 2012. As principais áreas de concentração dos Programas onde os trabalhos foram produzidos são: Serviço Social (68\%), Política social (13\%) e Educação (13\%), o que corresponde a atual configuração dos Programas de Pós-Graduação em Serviço Social: 18 Programas em Serviço Social (58\%), 6 em Política Social (19\%), 4 em Serviço Social ou outra área temática (13\%), 3 em Política Pública, sendo um combinado com Desenvolvimento Local (10\%) (CAPES, 2015).

As delimitações de tema mais frequentes, obtidas através da leitura dos resumos das teses e dissertações, cujo tema central foi a Formação, foram: Supervisão (17\%), Formação Profissional e Educação Permanente $(12 \%)$, Estágio $(10 \%)$ e EAD $(9 \%)$. No que se refere à metodologia de pesquisa, destacaram-se: a empírica (49\%), a documental (31\%), a bibliográfica (16\%) e 4\% não informaram este dado no referido resumo.

Com base nesses dados e, em consonância com os estudos já referenciados, confirma-se que os objetos de estudo da área sobre Formação são determinados, diretamente, pela conjuntura da política de educação superior, bem como pelas respostas profissionais dadas à mesma. Nessa perspectiva, é possível concluir que, por exemplo, a temática da Supervisão cuja maior incidência ocorreu no ano de 2000 (17\% das produções), após um intervalo de seis anos sem integrar o rol de temáticas das teses e dissertações, retornou com uma produção relativamente distribuída pelos anos que se seguiram representando, juntamente com a temática do Estágio (10\% das produções), um dos principais temas de interesse na pesquisa sobre formação. Esse dado decorre, certamente, dos novos desafios postos a formação profissional que, orientada pelo atual projeto de formação, vem empreendendo importantes conquistas na categoria profissional, a saber: a Resolução do CFESS N 533/2008 que regulamentou a supervisão de estágio em Serviço Social, bem como a construção da Política Nacional de Estágio, em 2010, que materializou o fruto de um trabalho coletivo que expressou "[...] uma demanda histórica da profissão e um importante ganho para as UFAS na direção da qualidade da formação e do exercício da supervisão na área” (LEWGOY; MACIEL; REIDEL, 2013, p. 99).

A temática Formação Profissional e Educação Permanente com 12\% das ocorrências se concentrou, especialmente, nos últimos dois anos analisados (2011 e 2012), juntamente com a temática do Ensino à Distância (EAD) que atingiu seu pico, no ano de 2011, com cinco produções. Ambas refletem o processo de busca pela qualidade da formação na área, uma vez que a capacitação e atualização permanente é um dever do profissional; assim como os processos de mercantilização e precarização do ensino superior, a partir da ampliação da modalidade EAD e da massificação das vagas na área que indicam os efeitos da ofensiva neoliberal na formação dos assistentes sociais, colocando em xeque, o Projeto Ético-Político da categoria. Silva e Carvalho (2005, p. 196), referem que o Serviço Social brasileiro sofreu avanços no que 
diz respeito à formação profissional, a partir do seu processo de ruptura, empreendendo um "salto qualitativo na área da formação profissional com o desenvolvimento de um projeto a partir das novas alternativas de intervenção profissional em construção; da inserção do Serviço Social no contexto universitário; do avanço da produção acadêmica e da pós-graduação".

$\mathrm{Na}$ atualidade, com base nos dados apresentados do período mais recente, constatamos que a quantidade de trabalhos produzidos pela área, no âmbito da pós-graduação, se apresenta como uma contribuição ímpar para a apreensão crítica e analítica desse objeto de estudo. Igualmente, se destaca a linearidade dessas produções, ocupando entre 4,6 a 11\% da produção da área na totalidade do período histórico citado (1975-2012). Entretanto, ao considerarmos a conjuntura da política de educação superior e os dados da área (número de cursos, diplomados, ensino à distância, entre outros), apontamos a necessidade de ampliação de estudos acerca da temática da Formação, considerando as radicais alterações que se processaram na mesma, no final do século 20 e deste início de século 21, e a necessidade de estabelecer os nexos entre as mesmas e a referida conjuntura, a fim de evitarmos o trato isolado e atomizado das temáticas que vem sendo problematizadas pela produção de conhecimento do Serviço Social.

\section{A contribuição dos líderes dos grupos de pesquisa na área da Formação}

Apresentamos, a seguir, a sistematização dos dados obtidos junto aos líderes dos grupos de pesquisa da área, a partir da análise de conteúdo das respostas obtidas num questionário on line. Foram enviados questionários para os 37 Grupos de Pesquisa do país que pesquisam o tema da formação, segundo dados obtidos no Diretório dos Grupos do Conselho Nacional de Desenvolvimento Científico e Tecnológico (CNPq).

No que se refere à caracterização desses Grupos, conforme a localização dos mesmos, no território nacional se evidencia o destaque para as Regiões Nordeste (38\%), Sudeste (32\%) e Sul (22\%) que concentram $92 \%$ do número total dos grupos no Brasil. Quanto à natureza dos Programas de Pós-Graduação em Serviço Social, ao contrário dos dados da graduação, esta indica que, apenas 7 deles são privados (23\%), sendo 24 públicos (77\%), o que nos permite afirmar que a pós-graduação no país é alavancada pela iniciativa pública. Este fato se expressa, também, na distribuição dos grupos de pesquisa por tipo de IES, enquanto 7 estão vinculados a IES privadas (18\%), 32 encontram-se em IES públicas (82\%).

Feita essa caracterização dos grupos de pesquisa, passamos a apresentar os dados coletados e obtidos junto a $20 \%$ dos seus líderes. No que diz respeito às principais tendências na formação em Serviço Social no Brasil, os sujeitos pesquisados sinalizaram, especialmente, a mercantilização, o empresariamento e a frágil fundamentação teórica da área expressa pelo ecletismo e pela dificuldade em superar a dicotomia entre teoria e prática:

Algumas unidades de formação são como empresas que respondem exclusivamente aos interesses do mercado (S2) [...] percebo no cenário nacional a tendência ao aligeiramento do ensino em detrimento da qualidade na formação (S2).

Grave debilidade no ensino das três dimensões formativas, inclusive com a quase ausência de estágio (S1). Debilidade no ensino da dimensão teórico-metodológica e ético-política (S1).

Discurso ideológico de postura crítica com poucas bases analíticas fundamentadas teoricamente ou em pesquisas empíricas (S6).

Convivem duas tendências básicas: uma mais crítica, com influencias do pensamento marxiano; e outra permeada pelo ecletismo, com a redução do projeto profissional ao campo do possível e a um relativo tecnicismo (S7).

Os profissionais ainda se referiram a questões como o detrimento da qualidade na formação, as mudanças nas demandas profissionais e nas exigências de novas competências profissionais e diferenciam, fortemente, a formação ofertada por modalidade de ensino (presencial ou à distância) ou em função da natureza das UFAS (pública ou privada). No seu conjunto, tais posicionamentos traduzem a fragilização que se encontra a formação, fruto da conjuntura da política de educação superior, mas, também nas dificuldades em garantir a materialização do atual projeto de formação que se ancora em fundamentos históricos, teóricos e metodológicos consistentes e rigorosos na "relação direta com projetos societários e, portanto, com perspectivas de organização e ação da classe trabalhadora nas relações sociais" (PINTO, 2014, p. 673).

No que se refere aos principais desafios na formação em Serviço Social no Brasil, destacamos dois deles: a articulação no ensino, indicada pela reprodução do distanciamento entre graduação e pós-graduação, mas, também, nas ações pedagógicas voltadas para a materialização do tripé ensino, pesquisa e extensão; o reconhecimento das particularidades regionais; a garantia da direção social da formação e a materialização das 
diretrizes curriculares; a relação persistente que separa os profissionais da prática e da academia; a da qualidade da formação, expressa nas duas modalidades de ensino (presencial e à distância, esta mais significativa), na precarização do trabalho docente e na frágil apreensão dos fundamentos da profissãa. Os extratos, a seguir, permitem a compreensão dos mesmos:

Garantir uma perspectiva crítica que mantenha a direção do Projeto Ético e Político profissional; Materializar as Diretrizes Curriculares não só formalmente, em seus projetos político-pedagógicos, mas que de fato se garanta isso no processo de ensino-aprendizagem (S2).

Desafio de conseguir como docente alcançar os objetivos de uma formação de qualidade em face de precarização do trabalho docente (S2).

Atual contexto socioeconômico, cuja precarização do ensino vem trazendo rebatimentos na formação profissional (S3).

Chama a atenção, nestes extratos, o desafio de enfrentar os rebatimentos da conjuntura de precarização do trabalho docente e a urgência de "interpretar as determinações e dinâmicas que envolvem o trabalho docente associado ao novo ordenamento das políticas educacionais e as repercussões para o projeto de formação dos assistentes sociais" (PINTO, 2014, p. 674).

Ao questionarmos, os líderes dos grupos de pesquisa, sobre como caracterizam a formação em Serviço Social no Brasil em termos do seu contexto e características atuais, os profissionais destacaram a relação da estrutura e da conjuntura com o projeto de formação profissional, onde se verifica uma relação contraditória, pois, se por um lado, muitas UFAS brasileiras buscam a materialização das Diretrizes Curriculares e do fortalecimento do Projeto Ético-Político; por outro lado, acompanhamos a mercantilização do ensino sob os ditames dos interesses do capital:

Uma formação em construção, que vem buscando caminhos para atender aos requisitos do projeto éticopolítico, em um contexto totalmente avesso ao que o mesmo preconiza. Por isto, muitas vezes, no processo de formação se cai nas armadilhas do militantismo, teoricismo ou tecnicismo (S3).

Superamos nas diretrizes e no Código de Ética o conservadorismo, instalando um perfil crítico à ordem burguesa no plano normativo. Mas no plano da formação efetiva não é o que predomina, porque o ideologismo de algumas escolas afasta os graduandos de posições hegemônicas aproximando-os de posições mais ecléticas ou pós-modernas (S1).

A concepção de educação (prática pedagógica) conservadora baseada exclusivamente em aulas expositivas em uma relação onde o docente dita o que o estudante deve saber e dizer (S6).

A reatualização do conservadorismo emerge com força nesses extratos, expressa pela crítica dos pesquisadores à realidade vivenciada na formação, e que se traduz nas dificuldades em trabalhar na perspectiva de uma formação sustentada pela Teoria Social crítica e, mediada, por uma educação emancipatória (Mészáros, 2008).

Em relação às principais influências da contrarreforma da educação superior brasileira para a formação em Serviço Social, cinco dos respondentes concordam que vivemos um processo de contrarreforma, e dois não. Os que defendem a ideia da contrarreforma destacam a mercantilização da formação: conservadora e com ideário neoliberal; expansão de oferta de cursos sem garantia de qualidade; precarização do ensino; desmonte do direito à educação; e privatização do ensino. Dos que não partilham dessa ideia, dizem que o que houve foi uma reforma prevista, organizada e estruturada a partir da LDB, expressando uma visão instrumental da política.

Sobre as relações e influências que podem ser estabelecidas entre a configuração atual da política de educação superior e a formação em Serviço Social, além das já destacadas, os sujeitos pesquisados sinalizaram: o trabalho precário do docente; a fragilidade das políticas de assistencial estudantil; os cortes de orçamento na política de educação; e a mudança no perfil dos discentes.

No que diz respeito à produção de conhecimento acerca da formação em Serviço Social no Brasil, os líderes dos grupos avaliaram essa produção, a existência ou não de uma ênfase teórica, assim como as temáticas mais incidentes, da seguinte forma: nenhum a considera muito boa; três a consideram boa em função do aumento na produção nos últimos anos, especialmente, nos anais de eventos e nas revistas; acesso ampliado às referências latino americanas; consistência da produção dos Programas de Pós Graduação; Interlocução com outras áreas de conhecimento; Avanço na análise crítica da conjuntura e seus rebatimentos na formação, mas com o destaque de, ainda, ser necessário avançar no debate das dimensões formativas e do trabalho profissional; três a consideram regular em razão da pouca produção; da ampliação 
de docentes interessados no tema da formação em Serviço Social e da educação superior; da produção centrada na crítica a educação superior sem o devido aprofundamento; e, por fim, um a considera ruim, pois avalia que há pouca produção na área sobre o tema formação.

Todos os pesquisadores acreditam haver uma ênfase teórica mais recorrente, na apreensão da formação na área, e citaram: o Marxismo (4); a Teoria Crítica (2); e o Método Histórico Dialético (1), apontando para um consenso de que ela é uniforme, ainda que a identifiquem de diferentes modos, como tratamos de conservar neste item. Em relação às temáticas mais incidentes, na apreensão da formação na área, foram identificadas: a relação teoria e prática; a formação; os fundamentos; o trabalho profissional; o contexto socioeconômico e os seus rebatimentos na formação; o estágio; as diretrizes curriculares; a Questão Social e o projeto ético-político.

As lacunas identificadas nas produções sobre formação na área estão relacionadas à demanda por mais pesquisas que tratem dos seguintes temas: dimensão técnicooperativa (3); mudanças contemporâneas no espaço sócio ocupacional; método; ética; formação profissional (2); projeto ético-político (2); estágio em Serviço Social (2); fundamentos; ensino - aprendizagem; novas tecnologias; produção de conhecimento; aspectos multiprofissionais e interdisciplinares; docência; formação Política; e dimensão educativa da profissão.

Por fim, trazemos o que pensam os sujeitos pesquisados sobre o tema do futuro da formação em Serviço Social, destacando os depoimentos que referem um cenário de retrocesso, devido à tendência da supremacia do ensino a distância, o sucateamento do ensino presencial e público, acompanhando do elitismo no ensino presencial privado.

A necessidade de construção de estratégias políticas envolvendo não somente o Serviço Social, mas a classe trabalhadora, articulada aos movimentos sociais, com vistas ao fortalecimento de uma posição política contrária ao neoliberalismo e todos os desmontes que o mesmo vem produzindo, inclusive, na política de educação superior também emergiu como uma demanda para o futuro. Acompanhada

... o futuro da formação
dependerá das condições
objetivas existentes e da
capacidade de organização e
articulação das entidades da
categoria, no compasso de uma
produção de conhecimento
sintonizada com os desafios e
tendências que a
contemporaneidade impõe à
profissão, no âmbito da sua
formação.
da necessidade de rever o distanciamento dos profissionais que estão na academia e dos demais, bem como da realidade concreta dos usuários. É preciso "sair da academia" e ir ao encontro da população com quem trabalham os assistentes sociais, que estão inseridos em diversos espaços sócio ocupacionais, é um dos registros frequentes dos sujeitos pesquisados. Nessa direção, complementam que o Serviço Social precisa avançar em pesquisas e debates (teóricos e políticos) que deem fundamentação, rigor técnico e científico para o exercício profissional.

Em síntese, para os líderes dos grupos de pesquisa, o futuro da formação dependerá das condições objetivas existentes e da capacidade de organização e articulação das entidades da categoria, no compasso de uma produção de conhecimento sintonizada com os desafios e tendências que a contemporaneidade impõe à profissão, no âmbito da sua formação.

\section{Considerações finais}

A conformação contemporânea da formação em Serviço Social vem sendo, diretamente, determinada pela conjuntura da política de educação superior no Brasil, vigente desde 1996, quando se passou a constatar uma radical transformação no número de instituições de ensino superior, de alunos e de diplomados; além da inserção da modalidade de ensino à distância na área. No que se refere à produção de conhecimento sobre Formação se constatou que este é um dos temas prioritários da agenda científica (e política) da categoria profissional, neste início de século 21, entretanto, os dados apresentados sobre ela sinalizam a necessidade de incremento dessa produção, pois se verificou que as publicações giram em torno de, no máximo, $11 \%$ da totalidade da produção da área. As ênfases dadas ao trato da categoria teórica Formação, nas produções mais recentes, indicam sintonia com as pautas mais contemporâneas da profissão (especialmente estágio e supervisão), mas não podem se esgotar nelas mesmas, pois estas se originam na 
conjuntura onde a formação está inserida e onde os estudos são mais escassos. Aqui se identifica uma lacuna que requer uma ampliação das pesquisas, já que a conjuntura adversa da política de educação vem incidindo na configuração da formação na área.

Na perspectiva dos líderes dos grupos de pesquisa se constatou um conjunto de tendências e desafios que convocam os mesmos (e a categoria profissional) para uma maior aproximação com o seu objeto de estudo, articulando o seu trabalho com os desafios que se colocam para as instituições de ensino e para o exercício profissional. E, ainda, construindo mediações com outras categorias profissionais, movimentos sociais, usuários e as próprias organizações da categoria profissional, pois é sabido que a conjuntura atual da formação em Serviço Social se insere num projeto mais amplo de formação de trabalhadores, de condições para o trabalho docente e de projeto para a universidade brasileira.

\section{Referências}

ASSOCIAÇÃO BRASILEIRA DE ENSINO E PESQUISA EM SERVIÇO SOCIAL (ABEPSS). Diretrizes Gerais para o Curso de Serviço Social. Rio de Janeiro: 1996.

ALMEIDA, B. de L. F. de; MENDES, J. M. R. As recentes tendências da pesquisa em Serviço Social. Revista Serviço Social \& Sociedade. São Paulo: Cortez, 2014. №120, p.640-661, out./dez.2014.

BOURDIEU, Pierre. O campo científico. In: ORTIZ, R. P. B. Coleção Grandes Cientistas Sociais. São Paulo: Editora Ática, 1983.

CAPES. Portal CAPES. 2015. Disponível em: http://www.capes.gov.br. Vários acessos.

CARVALHO, D. B.; SILVA, M. O. da. Serviço Social, Pós-Graduação e produção do conhecimento no Brasil. São Paulo: Cortez, 2005. CONSELHO FEDERAL DE SERVIÇO SOCIAL (CFESS). Educação não é fast-food: Diga não para a graduação à distância em Serviço Social. Brasília - DF, 2011. . www.cfess.org.br. Acesso em: Mar. 2015.

CONSELHO NACIONAL DE DESENVOLVIMENTO CIENTíFICO E TECNOLÓGICO. Diretório dos Grupos de Pesquisa. Disponível em: http://lattes.cnpq.br/web/dgp/grupo-pesquisa. Vários acessos. . Plataforma Carlos Chagas. http://carloschagas.cnpq.br. Vários acessos.

IAMAMOTO, M. V. A formação acadêmico-profissional no Serviço Social brasileiro. In: Revista Serviço Social e Sociedade, São Paulo: Cortez, Nº120, p.609-639, out./dez.2014.

KAMEYAMA, N. A trajetória da produção de conhecimentos em Serviço social: avanços e tendências (1975 a 1997). In: Cadernos ABESS, São Paulo, No8, P.33 a 76, 1998.

LEWGOY, A. M. B.; MACIEL, A. L. S.; REIDEL, T. A formação em Serviço Social no Brasil: contexto, conformação e produção de conhecimento na última década. In: Temporalis. Brasília (DF). p. 91 a 111, jan.jjun. 2013.

LIMA, K. Contrarreforma na Educação Superior: de FHC a LULA. Editora Xamã, 2007.

MACIEL, A. L. S. Universidade em crise: uma travessia necessária para a formação em Serviço Social. Tese de Doutorado. Porto Alegre: PUCRS, 2006.

. A formação em Serviço Social no contexto da política de educação superior brasileira: configurações, tendências e desafios. Projeto de pesquisa de produtividade. Porto Alegre, 2014.

. ARAÚJO, G.; STEIMETZ, G. A produção de conhecimento sobre formação em serviço social: historicidade, configuração e contribuição. In: Anais do Seminário Nacional de Serviço Social, trabalho e Politica Social. Florianópolis, 2015.

MÉSZÁROS, I. A educação para além do capital. Trad. Isa Tavares. São Paulo: Boitempo, 2008.

MEC/INEP. Censo da Educação Superior de 2013. Disponível em: www.inep.gov.br. Acesso: Jul. 2015.

PINTO, M. B. Condições sócio ocupacionais do trabalho docente e a formação profissional. In: Revista Serviço Social \& Sociedade. nº120. São Paulo: Cortez, 2014, p. 662-676, out./dez. 2014.

\section{Nota}

1 Os procedimentos para coleta, tratamento e análise dos dados foram organizados a partir do envio de questionários on line, respeitando os critérios éticos de pesquisa vigentes no país, mediante a apresentação do Termo de Consentimento Livre e Esclarecido, direcionado a todos os líderes dos grupos de pesquisa.

\section{Ana Lúcia Suárez Maciel}

alsmaciel@gmail.com

Doutora em Serviço Social pela Pontifícia Universidade Católica do Rio Grande do Sul (PUCRS).

Professora de Serviço Social da Pontifícia Universidade Católica do Rio Grande do Sul (PUCRS). 


\section{PUCRS}

Rua: Avenida Ipiranga, 6681, Partenon

Porto Alegre - Rio Grande do Sul - Brasil

CEP: 90619-900 